Article

\title{
Simultaneous Determination of 24 Antidepressant Drugs and Their Metabolites in Wastewater by Ultra-High Performance Liquid Chromatography-Tandem Mass Spectrometry
}

\author{
Ling-Hui Sheng ${ }^{1,2}$, Hong-Rui Chen ${ }^{3}$, Ying-Bin Huo ${ }^{3}$, Jing Wang ${ }^{2}$, Yu Zhang ${ }^{3}$, Min Yang ${ }^{3, *}$ \\ and Hong-Xun Zhang ${ }^{1, *}$
}

1 College of Resources and Environment, Graduate University of the Chinese Academy of Sciences, Beijing 100049, China; E-Mail: Shenglh@nim.ac.cn

2 National Institute of Metrology, Beijing 100013, China; E-Mail: wj@nim.ac.cn

3 Research Center for Eco-Environmental Sciences, Chinese Academy of Sciences, Beijing 100085, China; E-Mails: hr630@126.com (H.-R.C.); huo802@163.com (Y.-B.H.); zhangyu@rcees.ac.cn (Y.Z.)

* Authors to whom correspondence should be addressed; E-Mails: yangmin@rcees.ac.cn (M.Y.); hxzhang@ucas.ac.cn (H.-X.Z.); Tel.: +86-10-8825-6151 (H.-X.Z.); Fax: +86-10-8825-6152 (H.-X.Z.).

Received: 7 November 2013; in revised form: 14 January 2014 / Accepted: 15 January 2014 /

Published: 20 January 2014

\begin{abstract}
Antidepressants are a new kind of pollutants being increasingly found in wastewater. In this study, a fast and sensitive ultra-high performance liquid chromatography-tandem mass spectrometry method was developed and validated for the analysis of 24 antidepressant drugs and six of their metabolites in wastewater. This is the first time that the antidepressant residues in wastewater of Beijing (China) were systematically reported. A solid-phase extraction process was performed with $3 \mathrm{M}$ cation disk, followed by ultra-high performance liquid chromatography-tandem mass spectrometry measurements. The chromatographic separation and mass parameters were optimized in order to achieve suitable retention time and good resolution for analytes. All compounds were satisfactorily determined in one single injection within $20 \mathrm{~min}$. The limit of quantification (LOQ), linearity, and extraction recovery were validated. The LOQ for analytes were ranged from 0.02 to $0.51 \mathrm{ng} / \mathrm{mL}$. The determination coefficients were more than 0.99 within the tested concentration range $(0.1-25 \mathrm{ng} / \mathrm{mL})$, and the recovery rate for each target compound was ranged from $81.2 \%$ to $118 \%$ at $1 \mathrm{ng} / \mathrm{mL}$. This new developed method was successfully applied to analysis the samples collected from Beijing municipal
\end{abstract}


wastewater treatment plants. At least ten target antidepressants were found in all samples and the highest mean concentration of desmethylvenlafaxin was up to $415.6 \mathrm{ng} / \mathrm{L}$.

Keywords: pharmaceuticals; antidepressants drug; solid phase extraction; wastewater treatment plants

\section{Introduction}

In recent years, more and more human-use pharmaceuticals and their metabolites have been found in waters from municipal wastewater treatment plants (WWTPs) [1-5]. The antidepressant drugs are a class of neuroactive compounds that act as selective serotonin reuptake inhibitors and serotonin noradrenergic reuptake inhibitors, and some of their metabolites also retain the pharmacologic activity and are capable of contributing to serotonin reuptake inhibition [6-8]. The unaltered drugs or their main metabolites have been detected in municipal wastewaters in many countries [9-16].

Generally, the antidepressants exist in wastewater in low concentrations. However, their potent psychoactivity cannot be neglected. There are many reports on the potential effects of such compounds that may lead to physiological and behavioral changes in aquatic organisms and accumulate in their tissues [17-21]. Therefore, it is important to understand the environmental profile of these antidepressants and their metabolites in order to assess their potential ecological impact [22,23]. Gòmez et al. analyzed the effluents from three WWTPs in Spain using solid phase extraction (SPE) with an Oasis HLB sorbent, followed by gas chromatography-tandem mass spectrometry and found that the wastewater contained $8 \mathrm{ng} / \mathrm{L}$ of carbamazepine [24]. Lajeunesse et al. studied the basic antidepressants and their $\mathrm{N}$-desmethyl metabolites in raw sewage and wastewater from Montreal (Canada). Six basic antidepressants and four of their metabolites were detected by SPE and LC-MS/MS in raw sewage and roughly primary-treated wastewater with concentrations ranging from 2-346 ng/L [14]. Chen et al. found primidone and carbamazepine in wastewater effluent samples in Hebei Province of China with maximum concentrations of $74 \mathrm{ng} / \mathrm{L}$ and $103 \mathrm{ng} / \mathrm{L}$, respectively [25].

To our knowledge, only a few top-selling antidepressants found in wastewater were studied in different countries [9-16]. Simultaneous analysis of the most representative antidepressant drugs such as imipramine, nortriptyline, clozapine, mirtazapine, and their metabolites has not been reported up to now. The aim of this study is to investigate the occurrence of representative antidepressant drugs in wastewater from WWTPs in Beijing, China, which may facilitate a better understanding of the potential ecological and human health risks of these antidepressants and their metabolites in wastewater.

\section{Results and Discussion}

\subsection{Optimization of $L C-M S / M S$}

It has been shown that mass spectrometry is the most suitable tool for determination of trace environmental pollutants due to its high selectivity and sensitivity. Because most antidepressant drugs contain nitrogen-containing moieties with high proton affinities, in this study positive electrospray ionization (+ESI) was employed to analyze these antidepressant pharmaceuticals. Full-scan and 
MS/MS mass spectra of each compound were obtained by a 5500 Qtrap Tandem Mass Spectrometer via infusion of $50 \mathrm{ng} / \mathrm{L}$ individual standard solutions at a flow rate of $10 \mathrm{iL} / \mathrm{min}$. Two MRM transitions (quantifier and qualifier) were selected for each compound except norfluoxetine, fluoxetine and duloxetine, for which only one transition was monitored due to the poor fragmentation. The declustering potential (DP), collision energy (CE) and collision cell exit potential (CXP) for each analyte were optimized through direct infusion into mass spectrometer at the flow rate of $10 \mathrm{iL} / \mathrm{min}$. The optimized parameters of each mass transition were listed in Table 1.

Table 1. Mass spectrometer parameters for each analyte.

\begin{tabular}{|c|c|c|c|c|c|}
\hline Analyte & $\begin{array}{l}\text { Precusor } \\
\text { ion }(\mathrm{m} / \mathrm{z})\end{array}$ & $\begin{array}{c}\text { Product } \\
\text { ion }(\mathbf{m} / \mathbf{z})\end{array}$ & $\begin{array}{l}\text { Declustering } \\
\text { potential (V) }\end{array}$ & $\begin{array}{c}\text { Collision } \\
\text { energy (V) }\end{array}$ & $\begin{array}{c}\text { Collision } \\
\text { Exit potential(V) } \\
\end{array}$ \\
\hline \multirow[t]{2}{*}{ Citalopram } & 325.2 & $262.1 *$ & 110 & 26 & 17 \\
\hline & & 234 & & 36 & \\
\hline \multirow[t]{2}{*}{ Sertraline } & 306.2 & $275 *$ & 30 & 16 & 13.8 \\
\hline & & 159 & & 34 & \\
\hline \multirow[t]{2}{*}{ Venlafaxine } & 278.2 & $58 *$ & 60 & 20 & 9 \\
\hline & & 121 & & 34 & \\
\hline \multirow{2}{*}{$\begin{array}{l}\text { Desmethyl- } \\
\text { venlafaxine }\end{array}$} & 264.2 & $58 *$ & 65 & 50.7 & 9 \\
\hline & & 107 & & 49.7 & \\
\hline \multirow[t]{2}{*}{ Fluvoxamine } & 319.2 & $71 *$ & 30 & 18.3 & 16 \\
\hline & & 200 & & 26.9 & \\
\hline Desmethyl & 305.1 & $71 *$ & 44 & 15 & 13 \\
\hline Fluvoxamine & & 200 & & 32 & \\
\hline Fluoxetine & 310 & $44 *$ & 40 & 54 & 18.9 \\
\hline Norfluoxetine & 296.2 & $134 *$ & 37 & 8.5 & 11.2 \\
\hline \multirow{2}{*}{ Paroxetine } & 330.2 & $192 *$ & 100 & 28 & 18 \\
\hline & & 70.2 & & 50 & 8 \\
\hline Duloxetine & 298.2 & $154 *$ & 40 & 7.4 & 17 \\
\hline \multirow[t]{2}{*}{ Mirtazapine } & 266.1 & $195 *$ & 60 & 28.5 & 15.6 \\
\hline & & 72 & & 26.2 & \\
\hline \multirow[t]{2}{*}{ Desmethylmirtazapine } & 252 & $195 *$ & 60 & 30.9 & 17.9 \\
\hline & & 209 & & 28.6 & \\
\hline \multirow[t]{2}{*}{ Trazodone } & 372.3 & $148 *$ & 80 & 42 & 14 \\
\hline & & 176 & & 31 & \\
\hline \multirow[t]{2}{*}{ Clomipramine } & 315.2 & $86 *$ & 66 & 22.9 & 10 \\
\hline & & 58 & & 70 & \\
\hline \multirow[t]{2}{*}{ Norclomipramine } & 301.1 & $72 *$ & 56 & 20 & 15 \\
\hline & & 242 & & 30 & \\
\hline \multirow[t]{2}{*}{ Clozapine } & 327.1 & $270 *$ & 34 & 35 & 32.1 \\
\hline & & 296 & & 35 & \\
\hline \multirow{2}{*}{$\begin{array}{l}\text { Demethyl- } \\
\text { clozapine }\end{array}$} & 313.1 & $270 *$ & 100 & 33 & 15 \\
\hline & & 227 & & 38 & \\
\hline \multirow[t]{2}{*}{ Quetiapine } & 384.2 & $253 *$ & 110 & 30 & 19 \\
\hline & & 221 & & 50 & \\
\hline \multirow[t]{2}{*}{ Olanzapine } & 313.1 & $256.1 *$ & 80 & 29.7 & 20 \\
\hline & & 198 & & 50 & \\
\hline
\end{tabular}


Table 1. Cont.

\begin{tabular}{|c|c|c|c|c|c|}
\hline Analyte & $\begin{array}{l}\text { Precusor } \\
\text { ion }(\mathrm{m} / \mathrm{z})\end{array}$ & $\begin{array}{c}\text { Product } \\
\text { ion }(\mathbf{m} / \mathbf{z})\end{array}$ & $\begin{array}{l}\text { Declustering } \\
\text { potential (V) }\end{array}$ & $\begin{array}{c}\text { Collision } \\
\text { energy (V) }\end{array}$ & $\begin{array}{c}\text { Collision } \\
\text { Exit potential(V) }\end{array}$ \\
\hline \multirow[t]{2}{*}{ Imipramine } & 281.1 & $86 *$ & 66 & 23.5 & 9 \\
\hline & & 58 & & 59.8 & \\
\hline \multirow[t]{2}{*}{ Bupropion } & 240.1 & $184^{*}$ & 50 & 16.5 & 14 \\
\hline & & 131 & & 35 & \\
\hline \multirow[t]{2}{*}{ Amitriptyline } & 278.2 & $91 *$ & 80 & 29 & 13 \\
\hline & & 233.2 & & 23 & \\
\hline \multirow[t]{2}{*}{ Milnacipran } & 274.1 & $100 *$ & 30 & 25 & 12 \\
\hline & & 230 & & 15 & \\
\hline \multirow[t]{2}{*}{ Nortriptyline } & 264.2 & $91 *$ & 100 & 27 & 10 \\
\hline & & 105 & & 26 & \\
\hline \multirow[t]{2}{*}{ Doxepin } & 280.2 & $107.1 *$ & 58 & 28 & 13 \\
\hline & & 141 & & 31.5 & \\
\hline \multirow[t]{2}{*}{ Nordoxepin } & 266.1 & $107 *$ & 83.4 & 24.9 & 13 \\
\hline & & 91 & & 27 & \\
\hline \multirow[t]{2}{*}{ Fluphenazine } & 438.2 & $171.1 *$ & 60 & 32.3 & 12.2 \\
\hline & & 143.1 & & 39.2 & \\
\hline \multirow[t]{2}{*}{ Moclobemide } & 269.1 & $182 *$ & 60 & 27.4 & 11 \\
\hline & & 139 & & 39.6 & \\
\hline \multirow[t]{2}{*}{ Chlorpromazine } & 319.1 & $86 *$ & 85 & 24 & 17 \\
\hline & & 58 & & 53 & \\
\hline \multirow[t]{2}{*}{ Mianserin } & 265.2 & $208 *$ & 130 & 28 & 18 \\
\hline & & 118 & & 35 & \\
\hline
\end{tabular}

* Quantitative ion.

Since antidepressants and their metabolites exhibit basic characteristics due to their amine moieties, a source of protons in solution is essential to convert the basic substances into their cationic forms. In the present study, to improve ionization during the electrospray process, different concentrations of the mobile solutes ammonium formate and ammonium acetate in acetonitrile were tested. Meanwhile, the $\mathrm{pH}$ of the buffer was also evaluated. The highest signals sensitivity was observed when using ammonium acetate (10 mM, pH 3.0) as the mobile phase.

In order to get a good separation of all analytes, the retention and separation ability of CSH C18, HSS T3 C18 and BEH C18 columns were tested under the selected chromatographic conditions. The optimal peak shapes and resolution were achieved with BEH C18 column. The representative ion chromatograms of each compound obtained from a mixture of 30 standard samples are shown in Figure 1.

\subsection{Solid-Phase Extraction (SPE) Study}

To extract the target analytes from aqueous samples and reduce coextractive impurities from matrixes, two kinds of SPE sorbents, i.e., Oasis HLB and $3 \mathrm{M}$ Empore cation, were compared. The recovery percentage was used to estimate the SPE process efficiency for the selected analytes. In the 
case of HLB, which was used in most studies of trace drugs, the recovery was low, especially for olanzapine (44\%) and clozapine (40\%).

Figure 1. MRM chromatogram of 30 compounds obtained from a mixture of standard samples.
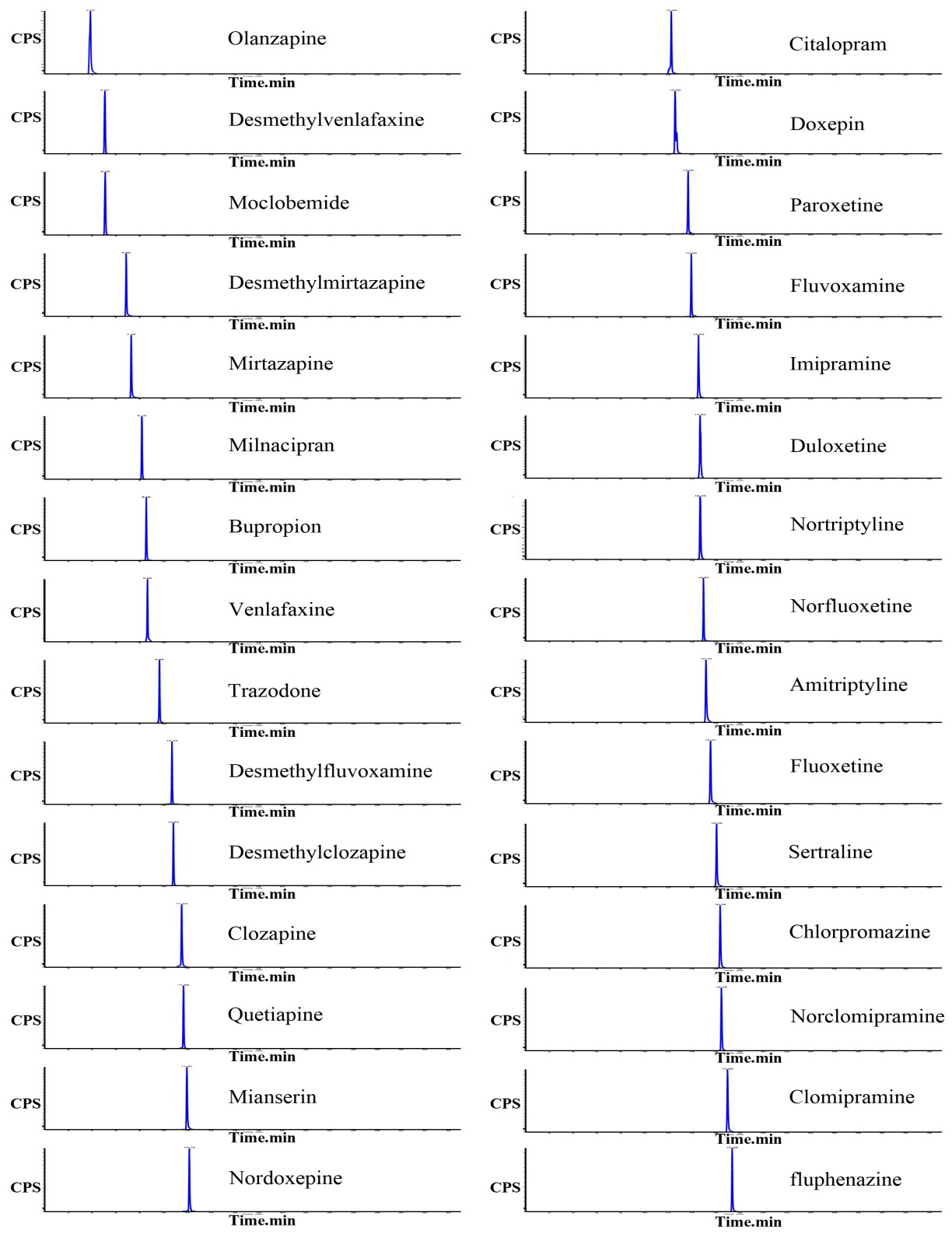

In contrast, the antidepressants and their metabolites were efficiently retained with higher recovery on $3 \mathrm{M}$ cation disk. The higher recovery on $3 \mathrm{M}$ cation disk was due to the filled cation-exchange sorbents which provide more effective sample clean-up for basic drugs by protonation of the free basic group. In the present study, the relative recovery rate for each target compound was from $81.2 \%$ to $118 \%$ at $1 \mathrm{ng} / \mathrm{mL}$. Therefore, the $3 \mathrm{M}$ cation disk was chosen for SPE because of its superior extraction recoveries for all analytes in the wastewater. 


\subsection{Method Validation}

The method was validated for linearity, limit of detection (LOD) and limit of quantification (LOQ) by the analysis of spiked milli-Q water samples. The results are listed in Table 2. In each case, a weighted linear regression line was applied. The LOD and LOQ were calculated as three and ten times signal to noise ratio at the $1 \mathrm{ng} / \mathrm{mL}$ concentration with an accuracy ranged from $80 \%$ to $120 \%$ and precision within $\pm 15 \%$ of the target concentration. The LODs ranged from 0.01 to $0.15 \mathrm{ng} / \mathrm{mL}$ and the LODs of norclomipramine, clozapine, quetiapine, nordoxepin and chlorpromazine were the lowest $(0.01 \mathrm{ng} / \mathrm{mL})$. The determination coefficient $\left(r^{2}\right)$ of all calibration curves was more than 0.99 within in the tested concentration range $(0.1-25 \mathrm{ng} / \mathrm{mL})$. Both selectivity and sensitivity of the established method were satisfactory, and no interfering substances presented at the appropriate retention times.

Table 2. Correlation coefficient, linearity range, LOD and LOQ of the method.

\begin{tabular}{|c|c|c|c|c|}
\hline Analyte & $\begin{array}{c}\text { Correlation } \\
\text { coefficient }\end{array}$ & $\begin{array}{l}\text { Concentration } \\
\text { range }(\mathrm{ng} / \mathrm{mL})\end{array}$ & $\begin{array}{c}\text { LOD } \\
(\mathrm{ng} / \mathrm{mL})\end{array}$ & LOQ (ng/mL) \\
\hline Citalopram & 0.9988 & $0.1-10$ & 0.04 & 0.11 \\
\hline Sertraline & 0.9989 & $0.1-10$ & 0.02 & 0.06 \\
\hline Venlafaxine & 0.9987 & $0.1-10$ & 0.03 & 0.09 \\
\hline Desmethylvenlafaxine & 0.9979 & $0.1-10$ & 0.05 & 0.15 \\
\hline Fluvoxamine & 0.9992 & $0.1-10$ & 0.07 & 0.23 \\
\hline Desmethylfluvoxamine & 0.9998 & $0.5-25$ & 0.09 & 0.32 \\
\hline Fluoxetine & 0.9986 & $0.1-10$ & 0.12 & 0.50 \\
\hline norfluoxetine & 0.9998 & $0.5-25$ & 0.15 & 0.51 \\
\hline Paroxetine & 0.9990 & $0.1-10$ & 0.05 & 0.16 \\
\hline Duloxetine & 0.9980 & $0.1-10$ & 0.04 & 0.12 \\
\hline Mirtazapine & 0.9989 & $0.1-10$ & 0.02 & 0.06 \\
\hline Desmethylmirtazapine & 0.9989 & $0.1-10$ & 0.03 & 0.10 \\
\hline Trazodone & 0.9995 & $0.1-10$ & 0.02 & 0.06 \\
\hline Clomipramine & 0.9995 & $0.1-10$ & 0.03 & 0.08 \\
\hline Norclomipramine & 0.9985 & $0.1-10$ & 0.01 & 0.04 \\
\hline Clozapine & 0.9976 & $0.1-10$ & 0.01 & 0.04 \\
\hline Demethylclozapine & 0.9986 & $0.1-10$ & 0.05 & 0.16 \\
\hline Quetiapine & 0.9991 & $0.1-10$ & 0.01 & 0.03 \\
\hline Olanzapine & 0.9973 & $0.1-10$ & 0.05 & 0.17 \\
\hline Imipramine & 0.9996 & $0.1-10$ & 0.02 & 0.07 \\
\hline Bupropion & 0.9997 & $0.1-10$ & 0.04 & 0.13 \\
\hline Amitriptyline & 0.9971 & $0.1-10$ & 0.03 & 0.10 \\
\hline Milnacipran & 0.9983 & $0.1-10$ & 0.07 & 0.21 \\
\hline Nortriptyline & 0.9985 & $0.1-10$ & 0.03 & 0.10 \\
\hline Doxepin & 0.9949 & $0.1-10$ & 0.04 & 0.13 \\
\hline Nordoxepin & 0.9977 & $0.1-10$ & 0.01 & 0.04 \\
\hline Fluphenazine & 0.9975 & $0.1-10$ & 0.03 & 0.10 \\
\hline Moclobemide & 0.9993 & $0.1-10$ & 0.05 & 0.15 \\
\hline Chlorpromazine & 0.9962 & $0.1-10$ & 0.01 & 0.03 \\
\hline Mianserin & 0.9986 & $0.1-10$ & 0.04 & 0.14 \\
\hline
\end{tabular}




\subsection{Application to Environmental Analysis}

This method was applied to detect antidepressants and their metabolites in the wastewater from three WWTPs in Beijing. The compounds were detected and confirmed by comparing their retention time and MRM transitions Eight antidepressants and two metabolites were successfully found in all wastewater samples. The concentrations of the antidepressants and metabolites are listed in Table 3. The metabolite desmethylvenlafaxine was found at the highest concentration of $(415.6 \pm 32.9) \mathrm{ng} / \mathrm{L}$, while the desmethylmirtazapine was detected in the effluents of WWTPs at the lowest concentration of $(4.0 \pm 0.2) \mathrm{ng} / \mathrm{L}$. The measured concentrations of these antidepressants and their metabolites were consistent with the previous reports about wastewaters [14,26].

Table 3. Concentrations (ng/L) of antidepressants and their metabolites in wastewaters $(n=3)$.

\begin{tabular}{cccc}
\hline Analyte & WWTP1\# & WWTP2\# & WWTP3\# \\
\hline Citalopram & $20.6 \pm 2.0$ & $18.3 \pm 2.0$ & $28.8 \pm 3.5$ \\
Sertraline & $37.3 \pm 1.3$ & $40.6 \pm 4.0$ & $18.8 \pm 2.8$ \\
Venlafaxine & $31.8 \pm 4.3$ & $63.7 \pm 2.6$ & $30.3 \pm 4.6$ \\
Desmethylvenlafaxine & $52.3 \pm 2.7$ & $71.3 \pm 4.8$ & $415.6 \pm 32.9^{\text {a }}$ \\
Mirtazapine & $62.8 \pm 4.8$ & $76.3 \pm 5.8$ & $84.2 \pm 13.7$ \\
Desmethylmirtazapine & $4.0 \pm 0.2$ & $7.3 \pm 1.3$ & $10.1 \pm 1.5$ \\
Clomipramine & $101.7 \pm 11.6^{\text {a }}$ & $77.5 \pm 4.3$ & $92.3 \pm 10.7$ \\
Clozapine & $91.7 \pm 4.3$ & $53.4 \pm 4.8$ & $163.9 \pm 17.7^{\text {a }}$ \\
Imipramine & $10.8 \pm 0.6$ & $10.6 \pm 2.1$ & $10.9 \pm 1.1$ \\
Nortriptyline & $47.8 \pm 1.3$ & $35.1 \pm 5.1$ & $43.8 \pm 7.8$ \\
\hline
\end{tabular}

a: The concentration was calculated from a diluted (1:10) sample.

\section{Experimental}

\subsection{Chemicals and Reagents}

All solvents were of HPLC grade obtained from Merck (Darmstadt, Germany). Ammonium acetate and ammonium formate were purchased from Sigma-Aldrich (St. Louis, MO, USA). Chemical standards of the antidepressant drugs (citalopram, sertraline, venlafaxine, fluvoxamine, fluoxetine, paroxetine, duloxetine, mirtazapine, trazodone, clomipramine, clozapine, quetiapine, olanzapine, imipramine, bupropion, amitriptyline, doxepin, fluphenazine, moclobemide, mianserin, milnacipran) were purchased from National Institutes for Food and Drug Control of China (Beijing, China). Desmethyl -venlafaxine was purchased from Zibo Dingjin Chemical Co., Ltd (Shandong, China). Norfluoxetine, desmethylmirtazapine, desmethylvenlafaxine, desmethylfluvoxamine, chlorpromazine, demethylclozapine, norclomipramine, nortriptyline were purchased from Toronto Research Chemicals Inc. (North York, ON, Canada). Standard stock solutions of these compounds were prepared in methanol $(1 \mathrm{mg} / \mathrm{mL})$. Deionized water was purified using a Milli-Q water purification system (Merck Millipore, Bedford, MA, USA).

Water samples were collected between December 2012 and April 2013 from wastewater treat plants of Beijing. The water samples were vacuum filtered through $1 \mu \mathrm{m}$ glass fiber filters, followed by $0.22 \mu \mathrm{m}$ nylon membrane filters right after the sampling, and stored on $-40^{\circ} \mathrm{C}$ until the analysis. 


\subsection{Apparatus and Operation Conditions}

The chromatographic separations were performed using the Agilent 1290 UHPLC system (Agilent, Waldbronn, Germany) equipped with a BEH C18 column, $2.1 \times 150 \mathrm{~mm}, 1.7 \mu \mathrm{m}$ (Waters Corporation, Milford, MA, USA). Gradient elution was applied using $10 \mathrm{mM}$ ammonium acetate containing $0.1 \%$ formic acid (A) and acetonitrile (B) as the mobile phase and programmed as follows: the gradient started with $20 \%$ eluent B in 5 min and increased linearly up to $60 \%$ in $15 \mathrm{~min}$. Then, it decreased linearly again down to $20 \%$ in $5 \mathrm{~min}$. The flow rate was $0.3 \mathrm{~mL} / \mathrm{min}$.

All the samples were analyzed with a 5500Qtrap Tandem Mass Spectrometer (Applied Bioscience, Foster City, CA, USA). Quantification was achieved by using multiple reaction monitoring (MRM). The declustering potential (DP), collision energy (CE) and collision cell exit potential (CXP) for each compound were optimized, which are listed in Table 1. Additional instrumental parameters for all analytes were as follows: curtain gas (CUR) setting at 45 psi, spray voltage at 4,500 V, source temperature at $600{ }^{\circ} \mathrm{C}$, gas 1 at 60 psi and gas 2 at 50 psi.

\subsection{Sample Extraction}

To remove suspended material, the water samples were vacuum filtered through $1 \mu \mathrm{m}$ glass fiber filters, followed by $0.22 \mu \mathrm{m}$ nylon membrane filters right after the sampling. The $\mathrm{pH}$ of each $300 \mathrm{~mL}$ of filtered sewage was adjusted to around 3 with hydrochloric acid $(6 \mathrm{~mol} / \mathrm{L})$. An automated solidphase extraction system Dex4790 (Horizon Technology, Salem, NH, USA) and $47 \mathrm{~mm}$ cation disks (3M Corporation, St. Paul, MN, USA) were employed. SPE was performed at flow rates $30-40 \mathrm{~mL} / \mathrm{min}$. Before the sample loading, the disk was washed with $8 \mathrm{~mL}$ of methanol, $8 \mathrm{~mL}$ of Milli-Q water, and $8 \mathrm{~mL}$ of acidified ( $\mathrm{pH} 3$ ) water. Samples were loaded onto the disk by gravity, and then the disk was washed with $10 \mathrm{~mL}$ of Milli-Q water, $10 \mathrm{~mL} 10 \%$ methanol and vacuum dried for 5 min. Finally the target drugs were eluted using $12 \mathrm{~mL}$ of $8 \%$ ammonia solution in methanol. The eluate was evaporated to dryness at $40{ }^{\circ} \mathrm{C}$ under a gentle stream of nitrogen and reconstituted in $1 \mathrm{~mL}$ of $20 \%$ acetronitrile solution.

\section{Conclusions}

A method based on the application of UHPLC-MS/MS for the simultaneous determination of 24 antidepressants and six metabolites in WWTP wastewaters was developed and validated. This is the first time the determination of up to 30 psychoactive compounds in one injection is reported, and 10 compounds were determined in all the effluents from three WWTPs in Beijing. Of these analytes, four antidepressants and two metabolites (venlafaxine, desmethylvenlafaxine, mirtazapine, desmethylmirtazapine, imipramine, nortriptylin) were found for the first time. High sensitivity and lower LOD were obtained thanks to the use of characteristic transitions. This study revealed the prevalence of antidepressants and their metabolites in wastewater effluents. The method developed in this study proved to be a valuable tool in the analytical characterization of antidepressants and their metabolites in wastewater, and may be helpful for determination of these drugs in sediment samples. 


\section{Acknowledgments}

This study was supported by Major Science and Technology Program for Water Pollution Control and Treatment (2012ZX07313-001-07) and Special Fund for Quality Supervision Research in the Public Interest (200910107).

\section{Author Contributions}

Hong-Xun Zhang, Min Yang and Yu Zhang participated in designing the study. Ling-Hui Sheng, Hong-Rui Chen, Ying-Bin Huo and Jing Wang conducted the study and collected the data. Ling-Hui Sheng and Hong-Rui Chen analyzed the data and wrote the manuscript.

\section{Conflicts of Interest}

The authors declare no conflict of interest.

\section{References}

1. Baker, D.R.; Kasprzyk-Hordern, B. Spatial and temporal occurrence of pharmaceuticals and illicit drugs in the aqueous environment and during wastewater treatment: New developments. Sci. Total Environ. 2013, 454, 442-456.

2. Kovalova, L.; Siegrist, H.; Singer, H.; Wittmer, A.; McArdell, C.S. Hospital wastewater treatment by membrane bioreactor: Performance and efficiency for organic micropollutant elimination. Environ. Sci. Technol. 2012, 46, 1536-1545.

3. Jelic, A.; Fatone, F.; di Fabio, S.; Petrovic, M.; Cecchi, F.; Barcelo, D. Tracing pharmaceuticals in a municipal plant for integrated wastewater and organic solid waste treatment. Sci. Total Environ. 2012, 433, 352-361.

4. Jelic, A.; Gros, M.; Ginebreda, A.; Cespedes-Sánchez, R.; Ventura, F.; Petrovic, M.; Barcelo, D. Occurrence, partition and removal of pharmaceuticals in sewage water and sludge during wastewater treatment. Water Res. 2011, 45, 1165-1176.

5. Bisceglia, K.J.; Yu, J.T.; Coelhan, M.; Bouwer, E.J.; Roberts, A.L. Trace determination of pharmaceuticals and other wastewater-derived micropollutants by solid phase extraction and gas chromatography/mass spectrometry. J. Chromatogr. A 2010, 1217, 558-564.

6. DeVane, C.L. Metabolism and pharmacokinetics of selective serotonin reuptake inhibitors. Cell. Mol. Neurobiol. 1999, 19, 443-466.

7. Anderson, H.D.; Pace, W.D.; Libby, A.M.; West, D.R.; Valuck, R.J. Rates of 5 common antidepressant side effects among new adult and adolescent cases of depression: A retrospective US claims study. Clin. Ther. 2012, 34, 113-123.

8. Henry, A.; Kisicki, M.D.; Varley, C. Efficacy and safety of antidepressant drug treatment in children and adolescents. Mol. Psychiat. 2011, 17, 1186-1193.

9. Mohapatra, D.P.; Brar, S.K.; Tyagi, R.D.; Picard, P.; Surampalli, R.Y. Carbamazepine in municipal wastewater and wastewater sludge: Ultrafast quantification by laser diode thermal desorption-atmospheric pressure chemical ionization coupled with tandem mass spectrometry. Talanta 2012, 99, 247-255. 
10. Lajeunesse, A.; Smyth, S.A.; Barclay, K.; Sauvéc, S.; Gagnon, C. Distribution of antidepressant residues in wastewater and biosolids following different treatment processes by municipal wastewater treatment plants in Canada. Water Res. 2012, 46, 5600-5612.

11. Baker, D.R.; Očenášková, V.; Kvicalova, M.; Kasprzyk-Hordern, B. Drugs of abuse in wastewater and suspended particulate matter-Further developments in sewage epidemiology. Environ. Int. 2012, 48, 28-38.

12. Tarcomnicu, I.; van Nuijs, A.L.; Simons, W.; Bervoets, L.; Blust, R.; Jorens, P.G.; Neelsa, H.; Covaci, A. Simultaneous determination of 15 top-prescribed pharmaceuticals and their metabolites in influent wastewater by reversed-phase liquid chromatography coupled to tandem mass spectrometry. Talanta 2011, 83, 795-803.

13. Bahlmann, A.; Weller, M.G.; Panne, U.; Schneider, R.J. Monitoring carbamazepine in surface and wastewaters by an immunoassay based on a monoclonal antibody. Anal. Bioanal. Chem. 2009, 395, 1809-1820.

14. Lajeunesse, A.; Gagnon, C.; Sauvé, S. Determination of basic antidepressants and their $\mathrm{N}$-Desmethyl metabolites in raw sewage and wastewater using solid-phase extraction and liquid chromatography-tandem mass spectrometry. Anal. Chem. 2008, 80, 5325-5333.

15. Yu, K.; Li, B.; Zhang, T. Direct rapid analysis of multiple PPCPs in municipal wastewater using ultrahigh performance liquid chromatography-tandem mass spectrometry without SPE pre-concentration. Anal. Chim. Acta 2012, 738, 59-68.

16. Aranas, A.T.; Guidote, A.M., Jr.; Haddad, P.R.; Quirino, J.P. Sweeping-micellar electrokinetic chromatography for the simultaneous analysis of tricyclic antidepressant and â-blocker drugs in wastewater. Talanta 2011, 85, 86-90.

17. Fong, P.P.; Molnar, N. Antidepressants cause foot detachment from substrate in five species of marine snail. Mar. Environ. Res. 2013, 84, 24-30.

18. Smith, E.M.; Iftikar, F.I.; Higgins, S.; Irshad, A.; Jandoc, R.; Lee, M.; Wilson, J.Y. In vitro inhibition of cytochrome P450-mediated reactions by gemfibrozil, erythromycin, ciprofloxacin and fluoxetine in fish liver microsomes. Aquat. Toxicol. 2012, 109, 259-266.

19. Berg, C.; Backström, T.; Winberg, S.; Lindberg, R.; Brandt, I. Developmental exposure to fluoxetine modulates the serotonin system in hypothalamus. PLoS One 2013, 8, e55053.

20. Backhaus, T.; Porsbring, T.; Arrhenius, Å.; Brosche, S.; Johansson, P.; Blanck, H. Single-substance and mixture toxicity of five pharmaceuticals and personal care products to marine periphyton communities. Environ. Toxicol. Chem. 2011, 30, 2030-2040.

21. Neuwoehner, J.; Escher, B.I. The pH-dependent toxicity of basic pharmaceuticals in the green algae Scenedesmus vacuolatus can be explained with a toxicokinetic ion-trapping model. Aquat. Toxicol. 2011, 101, 266-275.

22. Li, H.; Sumarah, M.W.; Topp, E. Persistence of the tricyclic antidepressant drugs amitriptyline and nortriptyline in agriculture soils. Environ. Toxicol. Chem. 2013, 32, 509-516.

23. Niemi, L.M.; Stencel, K.A.; Murphy, M.J.; Schultz, M.M. Quantitative determination of antidepressants and their select degradates by liquid chromatography/electrospray ionization tandem mass spectrometry in biosolids destined for land application. Anal. Chem. 2013, 85, 7279-7286. 
24. Gómez, M.J.; Agüera, A.; Mezcua, M.; Hurtado, J.; Mocholí, F.; Fernández-Alba, A.R. Simultaneous analysis of neutral and acidic pharmaceuticals as well as related compounds by gas chromatography-tandem mass spectrometry in wastewater. Talanta 2007, 73, 314-320.

25. Chen, F.; Ying, G.G.; Kong, L.X.; Wang, L.; Zhao, J.L.; Zhou, L.J.; Zhang, L.J. Distribution and accumulation of endocrine-disrupting chemicals and pharmaceuticals in wastewater irrigated soils in Hebei, China. Environ. Pollut. 2011, 159, 1490-1498.

26. Metcalfe, C.D.; Chu, S.; Judt, C.; Li, H.; Oakes, K.D.; Servos, M.R.; Andrews, D.M. Antidepressants and their metabolites in municipal wastewater, and downstream exposure in an urban watershed. Environ. Toxicol. Chem. 2010, 29, 79-89.

Sample Availability: Not available.

(C) 2014 by the authors; licensee MDPI, Basel, Switzerland. This article is an open access article distributed under the terms and conditions of the Creative Commons Attribution license (http://creativecommons.org/licenses/by/3.0/). 